\title{
Mitochondrial DNA sequence divergence among some west European brown bear (Ursus arctos L.) populations. Lessons for conservation
}

\author{
E. RANDI*, L. GENTILE†, G. BOSCAGLI†, D. HUBER $\ddagger$ \& H. U. ROTH§ \\ */stituto Nazionale per la Fauna Selvatica, via Ca'Fornacetta 9, 40064 Ozzano dell'Emilia (BO), Italy, †Centro Studi \\ Ecologici Appenninici, Parco Nazionale d'Abruzzo, 67032 Pescasseroli (AQ), Italy, $\ddagger$ Veterinary faculty of the University of \\ Zagreb, Heinzelova 55, 41000 Zagreb, Croatia and \$Neumatt 15, 3323 Baeriswil, Switzerland
}

\begin{abstract}
We used the polymerase chain reaction and nucleotide sequencing to study mitochondrial DNA (mtDNA) genetic variability of brown bears (Ursus arctos) belonging to some western European populations. Demographic decline and isolation have apparently shaped genetic variability within and between populations. Small relict bear populations were apparently monomorphic and fixed for different mtDNA haplotypes. Genetic relationships among mtDNA haplotypes suggested the existence of a phylogeographic structure. We discuss the possible roles of historical and demographic factors in determining the observed genetic patterns. The low genetically effective size of the studied brown bear populations points to risks of continuing future loss of gene diversity and increase in inbreeding. Artificial gene flow through restocking could alleviate inbreeding depression in small isolated brown bear populations, and mtDNA phylogeographic relationships may provide a framework for their genetic management.
\end{abstract}

Keywords: brown bear, conservation genetics, cytochrome $b, D$-loop, mtDNA, Ursus arctos.

\section{Introduction}

The decline of most western European brown bear (Ursus arctos L.) populations was an ancient and persistent process (Curry-Lindahl, 1972). In Great Britain the brown bear was probably already extinct in the 10th century. Since then, the formerly continuous continental population has been decimated, particularly during the last three to four centuries, as a consequence of habitat destruction and direct human persecution (Sorensen, 1990). Brown bears survive in approximately 13 isolated populations (Fig. 1), some of which are highly endangered and at immediate risk of extinction (Servheen, 1990).

In Spain two isolated populations survive in the Cantabrian Mountains (Del Campo et al., 1990), and in the Pyrenees along the French border (Camarra \& Parde, 1990). The French brown bear population is probably reduced to only nine to 13 animals (Taberlet \& Bouvet, 1994). In the Alps, less than 10 animals (Osti,

*Correspondence.
1990) still persist in the Adamello-Brenta Provincial Park (Trentino-Alto Adige, Italy), and the population could be on the verge of extinction. In the Apennines, recent estimates (Boscagli, 1991) confirm that no more than 70-80 (optimistically 100) bears survive, of which only 49 or 50 are really protected within the Abruzzo National Park's boundaries. In the Balkans, the Dinara Mountains hold one of the largest European bear populations (over 2000 bears), ranging over some $60000 \mathrm{~km}^{2}$, mostly in Slovenia, Croatia, Bosnia Hercegovina, Montenegro and the former Yugoslav Republic of Macedonia (Huber \& Moric, 1989), and smaller areas in Albania and northern Greece (Mertzanis, 1990).

Some western European brown bear populations are on the verge of extinction, and exceptional conservation efforts will be necessary to secure their persistence (Boscagli, 1994). Negative trends in population size could be the consequence of both demographic and genetic processes (Lande, 1988). Small population size, low genetic variability and inbreeding depression are interactive negative forces which can, probably, be 
Fig. 1 Distributions of western European brown bear populations (redrawn after Servheen, 1990). Samples for this study were collected from the following localities: Abruzzo National Park, Italy (ABRUZZO); AdamelloBrenta Provincial Park, Italy (TRENTINO); Gorski Kotar region, Croatia (CROATIA).

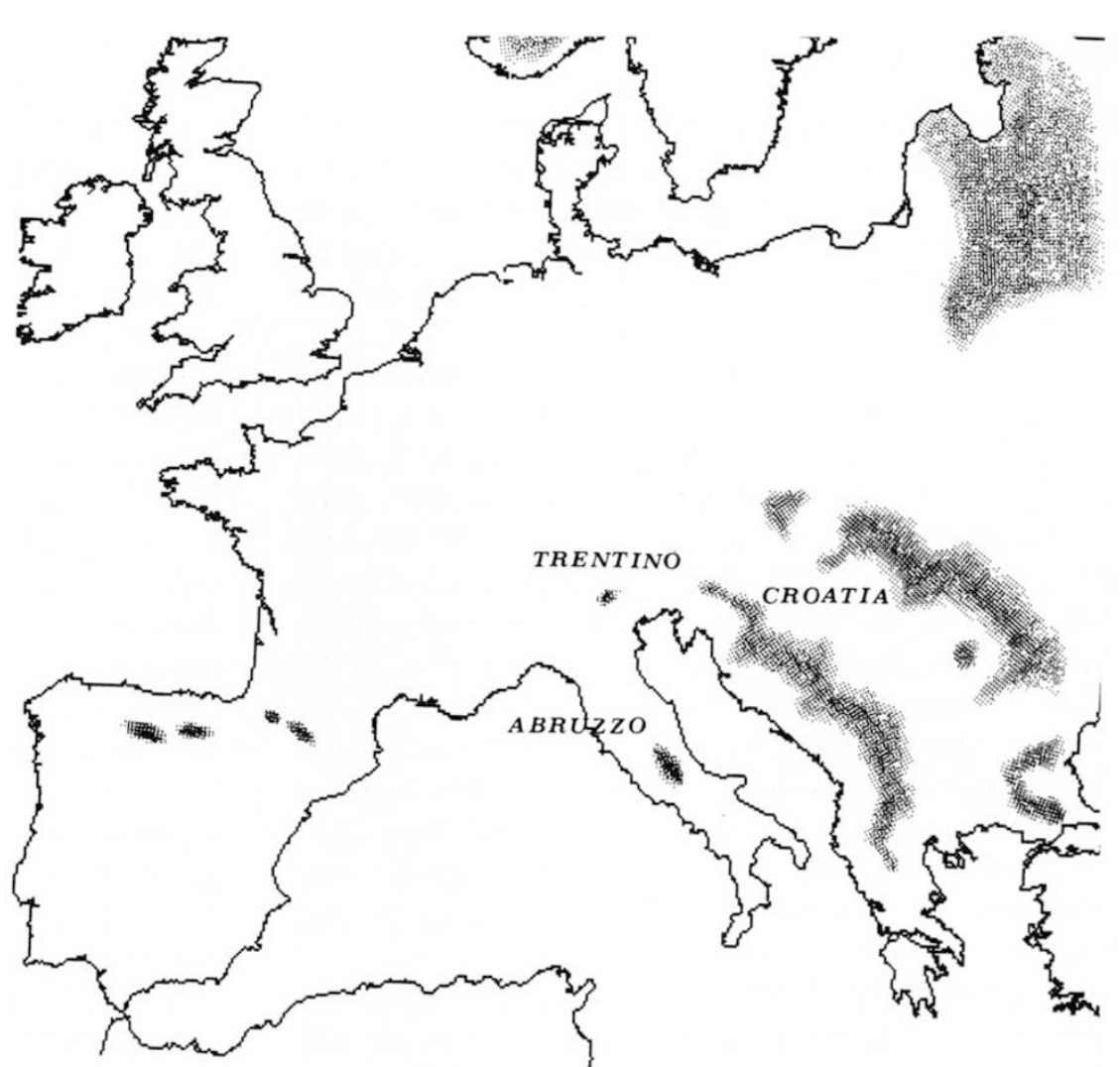

counteracted only through careful restocking. Artificial immigration of bears belonging to other populations could increase the mating chances of residents, introduce genetic variability into the populations, and alleviate the effects of inbreeding depression (Allendorf \& Servheen, 1986).

A strategy aiming to conserve and manage the western European relict bear populations requires, inter alia, detailed knowledge of their genetic structures. The brown bear's long-lasting history of demographic decline, fragmentation and isolation will have probably affected the genetic structure of the surviving populations. Measuring genetic diversity within populations allows indirect estimates of the effective population size (Avise et al., 1984) and of the expected increase in inbreeding per generation (Wright, 1931), which could expose the population to risks of inbreeding depression (Lacy, 1992). Reconstructing the phylogeographic relationships among populations (Avise et al., 1987), could allow the identification of distinct microevolutionary lineages, which constitute the background for a sound conservation strategy based on restocking of the endangered isolates (Avise, 1989).

Mitochondrial DNA (mtDNA) sequence variability has been successfully used to study intraspecific population genetics (Avise et al., 1987). Vertebrate mtDNA accumulates point mutations at an average rate 5-10 times higher than nuclear sequences; it is maternally inherited; and it does not recombine (Brown, 1985). Therefore, the analysis of mtDNA can supply information on the extent of genetic divergence among populations which have been submitted to recent bottlenecks, fragmentation and isolation (Avise et al., 1987).

We have studied mtDNA sequence variation in brown bear samples belonging to the two Italian populations: the central Apennines population, living in the Abruzzo National Park and surrounding mountains, and the Alpine population, living in the Adamello-Brenta Provincial Park (Fig. 1). Italian specimens were compared with brown bears sampled in Croatia (Gorski Kotar region). We have, moreover, sequenced mtDNA samples from captive bears of uncertain origins. DNA was extracted from blood and tissues, as well as from single hair roots and excrement collected in the field. Portions of the mtDNA cytochrome $b$ gene and of the control region ( $D$-loop) have been amplified using the polymerase chain reaction (PCR; Saiki et al., 1988), and then directly sequenced. The results of this study describe the effects of demographic histories on genetic variability of brown bear populations, indicate the existence of phylogeographic relationships among populations, and provide a basis for their genetic management. 


\section{Materials and methods}

The brown bear samples studied are listed in Table 1 . Wild animals were captured in the Abruzzo National Park, Italy. Blood samples were collected from anaesthetized animals. Tissue samples were collected from animals found dead, killed by road accidents or poaching acts (collectors: G. B., H. U. R., L. G.). F. Osti collected brown bear hair and excrement from the Adamello-Brenta Park, Italy. We assume, but cannot be sure, that these samples belong to at least two (possibly three) different animals, because they were collected in areas usually frequented by different bears. Brown bears from Croatia belong to the Gorski Kotar population. Three of them are free-born animals now living at Zagreb Zoo; the last one still lives in the wild. A captive bear of North American origin ( $U$. arctos middendorffi, Kodiak) was sampled at Zagreb Zoo (samples collected by D. H.). Captive bears of unknown wild origins were sampled at Bern Zoo (Switzerland) by H. R., and at Pescasseroli Zoo (Abruzzo National Park, Italy), by H. R., G. B. and L. G.

Total DNA was obtained from blood or tissues using standard proteinase K-SDS digestion and phenol/ chloroform/isoamyl alcohol extractions (Hillis et al., 1990); from hair roots using Chelex (Bio-Rad) resin (Walsh et al., 1991); and from excrement following Hoss et al. (1992). DNA was resuspended, and aliquots containing less than $0.1 \mu \mathrm{g}$ were used for each doublestrand PCR amplification with the following primer pairs.
1 L14841 and H15140 (Kocher et al., 1989) were used to amplify a 307-bp fragment of the mtDNA cytochrome $b$ gene $(c y t-b)$.

2 The two primers listed by Hoss et al. (1992), and based on sequences published by Shields \& Kocher (1991), were used to amplify a 88-bp fragment of the mtDNA control region (the $D$-loop).

These primers were chosen to obtain sequences comparable with other already published bear sequences (Shields \& Kocher, 1991; Taberlet \& Bouvet, 1992; Hoss et al., 1992). Furthermore, primers L15774 and H16498 (Kocher et al., 1989) were used to amplify a 300 -bp fragment spanning a portion of the mtDNA control region in the 10 brown bears from Abruzzo, in order to gain more information on withinpopulation genetic variability.

We used two three-temperature cycle programmes in a Perkin Elmer Cetus P9600 machine:

$193^{\circ} \mathrm{C}$ for $10 \mathrm{~s}, 50^{\circ} \mathrm{C}$ for $10 \mathrm{~s}, 72^{\circ} \mathrm{C}$ for $20 \mathrm{~s}$, repeated 30 times, to amplify DNA collected from blood and tissues;

$293^{\circ} \mathrm{C}$ for $10 \mathrm{~s}, 50^{\circ} \mathrm{C}$ for $10 \mathrm{~s}, 72^{\circ} \mathrm{C}$ for $30 \mathrm{~s}$, repeated 45 times, to amplify DNA collected from hair roots and excrement.

Double-strand DNA fragments were purified in lowmelting 2-3 per cent agarose (NuSieve, FMC) minigels, followed by phenol/chloroform/isoamyl alcohol extractions, and acetate/ethanol precipitation. DNA was sequenced using a Delta Taq cycle-sequencing kit (USB). Sequences were aligned by eye and analysed using the computer programs MEGA (Kumar et al., 1993) and PHYLIP (Felsenstein, 1989).

Table 1 Origins of the brown bears (Ursus arctos L.) studied

\begin{tabular}{|c|c|c|c|}
\hline Samples & $n$ & Origins & DNA source \\
\hline ABRUZZO & 10 & $\begin{array}{l}\text { Italy, Central Apennines } \\
\text { (Abruzzo), wild }\end{array}$ & Blood, tissues \\
\hline TRENTINO & 2 & $\begin{array}{l}\text { Italy, Eastern Alps } \\
\text { (Trentino), wild }\end{array}$ & Hairs, excrement \\
\hline CROATIA & 4 & $\begin{array}{l}\text { Croatia } \\
\text { (Gorski Kotar), wild }\end{array}$ & Blood, hairs \\
\hline KODIAK & 1 & $\begin{array}{l}\text { North America } \\
\text { (Zagreb Zoo, Croatia) }\end{array}$ & Blood \\
\hline CAPTIVE-2 & 1 & $\begin{array}{l}\text { Unknown } \\
\text { (Bern Zoo, Switzerland) }\end{array}$ & Blood \\
\hline CAPTIVE-3 & 1 & $\begin{array}{l}\text { Unknown } \\
\text { (Bern Zoo, Switzerland) }\end{array}$ & Blood \\
\hline CAPTIVE-4 & 1 & $\begin{array}{l}\text { Unknown } \\
\text { (Pescasseroli Zoo, Italy) }\end{array}$ & Blood \\
\hline CAPTIVE-5 & 1 & $\begin{array}{l}\text { Unknown } \\
\text { (Private Zoo, Italy) }\end{array}$ & Blood \\
\hline
\end{tabular}

Locations are mapped in Fig. 1. 


\section{Results}

Nucleotide sequences of the 307-bp mtDNA $c y t-b$ and 88-bp $D$-loop are shown in Tables 2 and 3, respectively. Nucleotide diversity among the $c y t-b$ sequences is lower than among the $D$-loop sequences. Brown bears from Abruzzo, Trentino and Croatia are monomorphic within populations, and share the same $c y t-b$ haplotype. The Pyrenean bear is different at three nucleotide positions (nos 14899, 14990 and 15019). The $D$-loop fragment is more variable: bears from Abruzzo have their own distinct haplotype, which is different at nucleotide no. 16 from the haplotype found in the Alpine bears. The Croatian bears are polymorphic, showing two haplotypes: the first one is shared with the Alpine samples, and is different from the second one at nucleotides nos 48 and 77. The brown bear from Romania is much more divergent.

Pairwise differences among mtDNA haplotypes are shown in Table $4(c y t-b)$ and Table 5 ( $D$-loop). Most mutations in the cyt-b sequences are transitions (Ts; purine/purine and pyrimidine/pyrimidine substitutions) at synonymous sites. Therefore, the predicted number of amino acid replacements is very low. Many transversions (Tv; purine/pyrimidine substitutions) are involved in comparisons between brown and American black bear (U. americanus) haplotypes (Table 4). The average $\operatorname{Tr} / \mathrm{Tv}$ ratio is $7: 1$. There are no Tv differences among the $D$-loop sequences (Table 5). Estimated percentage sequence divergences (Kimura, 1980 ) are higher among the $D$-loop than among $c y t-b$ haplotypes. The average percentage sequence divergence among brown bear $c y t-b$ haplotypes is 2.8 , while it is 10.7 , four times higher, among the $D$-loop haplotypes.

Phylogenetic relationships among the different $c y t-b$ haplotypes are shown in Fig. 2. The tree is the UPGMA tree computed by the program MEGA (Kumar et al., 1993) using Kimura's distance matrix (Table 4). The tree has been rooted using the American black bear as an outgroup. The North American brown bears split into two lineages: the first included Kodiak and captive bears, the second linked grizzly and polar bears $(U$. maritimus) and, clearly separated, the European brown bear haplotypes. The Pyrenean brown bear's mtDNA haplotype is related to the lineage including bears from the Apennines, the Alps and Croatia. The polar bear mtDNA sequences appear to be strictly related to the grizzly mtDNA. We have obtained the same groupings using different estimates of nucleotide divergence (i.e. percentage of nucleotide substitutions, Jukes-Cantor distance), and different tree-building methods (i.e. neighbour-joining, maximum parsimony with branchand-bound and heuristic searches; Kumar et al., 1993).
Notwithstanding the relatively short sequences examined, the groupings obtained with UPGMA and neighbour-joining procedures appear to be quite stable after 1000 bootstrap replicates, with the possible exception of the position of CAPTIVE- 4 which was weakly linked to the grizzly-polar bear and Alpine brown bear lineages (Fig. 2).

The phylogenetic relationships among the $D$-loop haplotypes are shown in Fig. 3 (UPGMA tree clustering using Kimura's distance matrix; Table 5). The clusters obtained using $c y t-b$ are confirmed with $D$-loop sequences, but the greater genetic variability of the $D$ loop reveals more details of the within-cluster relationships. Captive bears of unknown origins, except CAPTIVE-4, group with the Kodiak. Within the European brown bear lineage, the bear from Romania is the most divergent from the variant Croatian haplotype (CROATIA-4), from CAPTIVE-4, and from the Alpine bears, which are closely linked to the most frequent Croatian haplotype. The neighbour-joining procedure produced slightly different relationships within the Alpine-Apennine brown bear cluster, mainly due to the weak linking of CAPTIVE-4 with the other mtDNA haplotypes (Fig. 4). Phylogenetic relationships between species confirm the closeness of polar and grizzly bears (Cronin et al., 1991; Shields \& Kocher, 1991). Sequence divergence between polar and grizzly bears is lower than divergence among some of the brown bear haplotypes (Fig. 3). We have obtained similar relationships among brown bear mtDNA haplotypes using the parsimony programs DNAPARS and DNABOOT in PHYLIP (trees not shown).

\section{Discussion}

The analysis of 395-bp mtDNA sequences in western European and North American brown bears indicates two main points: (i) small relict bear populations are apparently monomorphic and fixed for different mtDNA haplotypes; and (ii) the relationships among haplotypes are not random, but show a phylogeographic structure.

The 10 Apennine brown bears we have studied share the same mtDNA sequence, which differs at one nucleotide position from the closely related sequence we have found in the Alpine and in three of the four Croatian bears. We sequenced $300 \mathrm{bp}$ more in the Apennine samples using primers L15774 and H16498 (Kocher et al., 1989), without finding any nucleotide substitution. Therefore, the 10 Apennine brown bears were monomorphic at a 695 bp sequence of their mtDNA. Recent results by Taberlet \& Bouvet (1994) indicate that brown bears from the Pyrenees, Sweden and Lapland are monomorphic within populations, after 
Table 2 Aligned nucleotide sequences showing the 41 variable positions in the 307-bp mtDNA cyt- $b$ gene of the brown bear

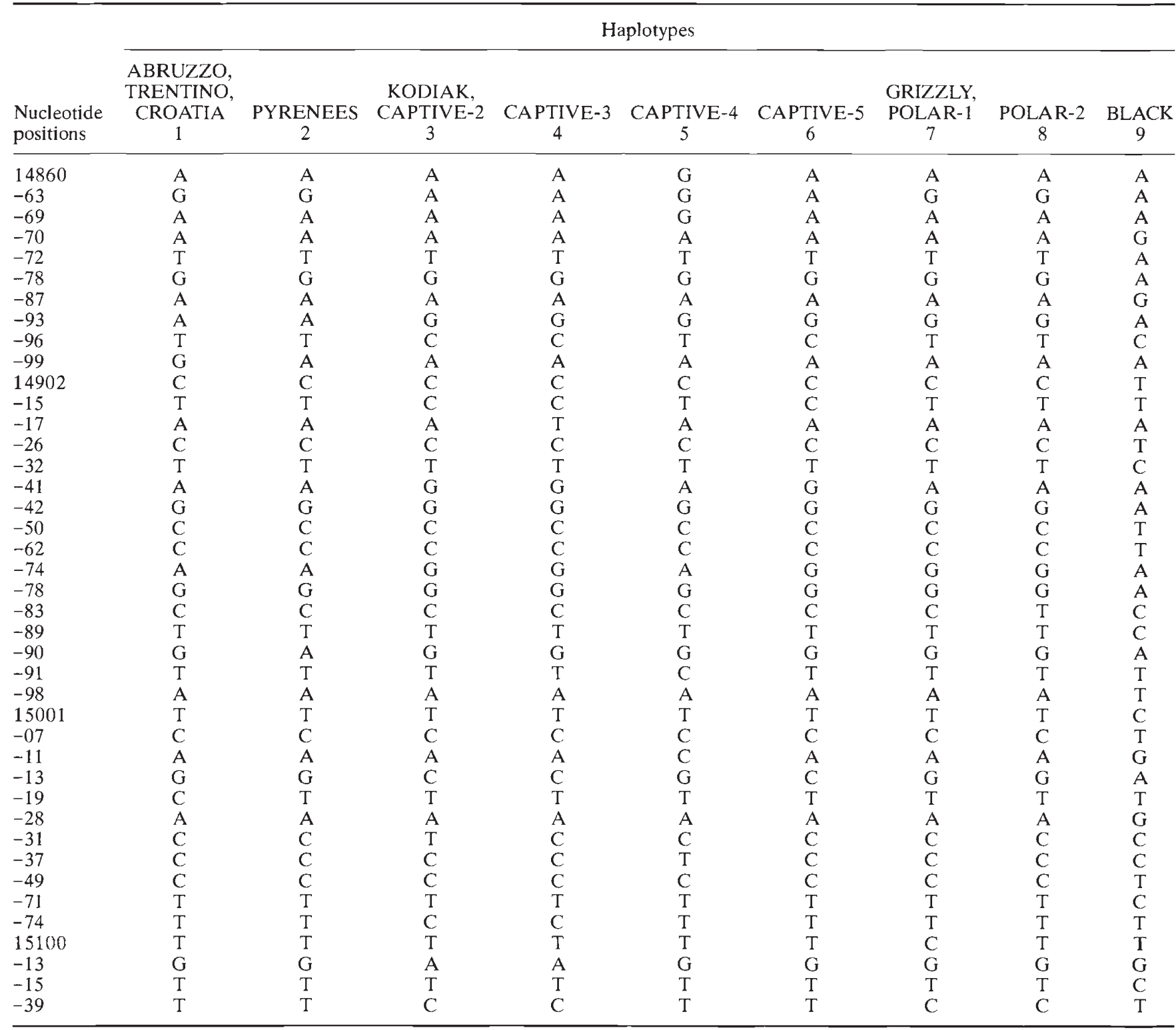

Nucleotide positions correspond to the human mtDNA sequence (Anderson et al., 1981).

The acronyms of west European brown bear samples are described in Table 1 .

Our sequences are compared with homologous sequences of a brown bear from the Pyrenees (PYRENEES; Taberlet \& Bouvet, 1992) and

Alaskan brown bears (GRIZZLY), polar bears (POLAR), and American black bear (BLACK), as published by Shields \& Kocher (1991).

the sequencing of 269 bp of the mtDNA control region.

Mitochondrial DNA is a haploid, maternallyinherited molecule, with an effective population size $\left(N_{e}\right)$ four times lower than for nuclear genes (Wilson et al., 1985). MtDNA is, therefore, sensitive to demographic processes, such as population fragmentation, isolation and bottlenecks. Avise et al. (1984) maintained that an isolated stable population will probably retain a single mtDNA haplotype after $4 N_{\mathrm{ef}}$ $\left(N_{\text {ef }}=\right.$ female $\left.N_{\mathrm{e}}\right)$ generations. Harris \& Allendorf
(1989) estimated that in grizzly bears $N_{\mathrm{e}}$ is about $0.2-0.3 N_{\mathrm{o}}$ (the observed population size). Apennine brown bear populations actually number, at best, 100 bears $\left(N_{\mathrm{o}}\right)$, which means $N_{\mathrm{e}}=20-30$. Given a sex ratio of 1:1 (Harris \& Allendorf, 1989), $N_{\mathrm{ef}}=10-15$. Therefore, $4 N_{\mathrm{cf}}=40-60$ generations. The estimated generation time is about 10 years in brown bears (Harris \& Allendorf, 1989), which means that in 400-600 years of isolation a population of $N_{\mathrm{o}}=100$ has a high probability of comprising a single mtDNA haplotype due to random drift alone. Historical information indicates 


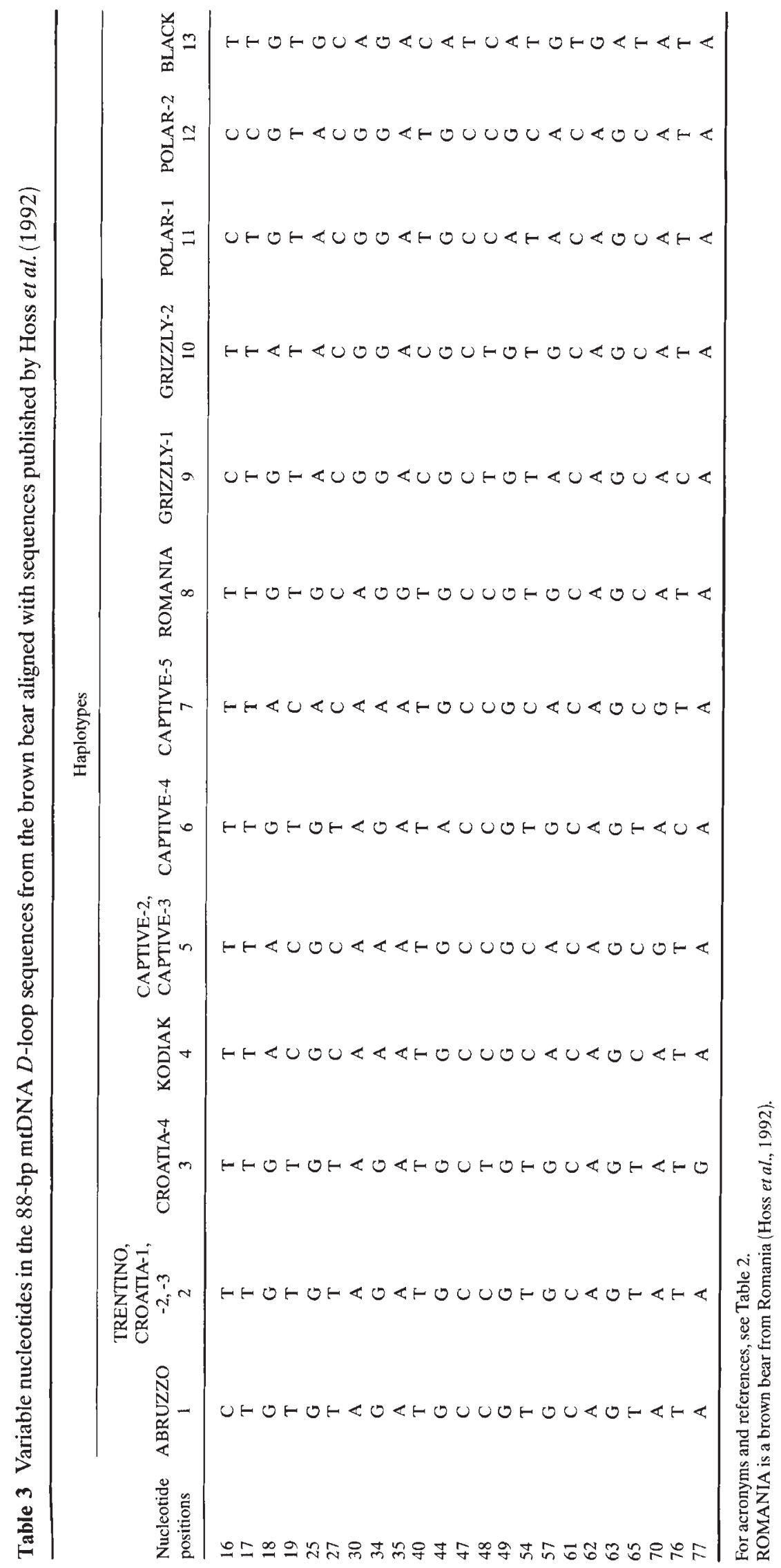


that the Apennine population has been isolated from the Alpine brown bears for about 400 years (Febbo \& Pellegrini, 1990), a consequence of habitat transformation and direct human persecution which caused the progressive eradication of the species from northern Italy. The observed mtDNA monomorphism is, therefore, the plausible result of random drift and stochastic extinction of maternal lineages since the isolation of the Apennine population. During the past centuries, the Apennine population must have been larger than the actual 100 animals, but this positive effect on $N_{\mathrm{e}}$ may have been offset by the persistent demographic declin-

Table 4 Pairwise differences among $c y t-b$ haplotypes (Table 2)

\begin{tabular}{rccccccccc}
\hline \multicolumn{10}{c}{ Haplotypes } \\
\cline { 2 - 9 } & 1 & 2 & 3 & 4 & 5 & 6 & 7 & 8 & 9 \\
\hline 1 & - & $3 / 0$ & $12 / 1$ & $11 / 2$ & $7 / 1$ & $8 / 1$ & $6 / 0$ & $5 / 0$ & $24 / 2$ \\
2 & 1.3 & - & $11 / 1$ & $10 / 2$ & $6 / 1$ & $7 / 1$ & $5 / 0$ & $5 / 0$ & $21 / 2$ \\
3 & 4.3 & 4.3 & - & $1 / 1$ & $13 / 2$ & $4 / 0$ & $8 / 1$ & $8 / 1$ & $27 / 3$ \\
4 & 4.3 & 4.3 & 0.7 & - & $12 / 3$ & $3 / 1$ & $7 / 2$ & $7 / 2$ & $26 / 4$ \\
5 & 2.7 & 2.3 & 5.0 & 5.0 & - & $9 / 2$ & $7 / 1$ & $7 / 1$ & $26 / 3$ \\
6 & 3.0 & 3.0 & 1.3 & 1.3 & 3.7 & - & $6 / 1$ & $6 / 1$ & $23 / 3$ \\
7 & 1.7 & 1.7 & 2.7 & 2.7 & 2.3 & 2.0 & - & $2 / 0$ & $26 / 2$ \\
8 & 2.0 & 2.0 & 3.0 & 3.0 & 2.7 & 2.3 & 0.3 & - & $26 / 2$ \\
9 & 8.7 & 8.0 & 10.0 & 10.0 & 10.0 & 8.7 & 9.0 & 9.4 & - \\
\hline
\end{tabular}

Upper right triangular matrix shows nucleotide substitutions partitioned into transitions/transversions. Lower left triangular matrix shows the estimated percentage sequence divergence among haplotypes (Kimura's (1980) twoparameters model). ing trend (Boscagli, 1991). The expected rate of loss of mtDNA variation in declining populations is highly accelerated (Avise et al., 1984).

Similar microevolutionary dynamics may have affected mtDNA sequence variability in most of the actual relict western European brown bear populations. Interestingly, four bears from the Gorski Kotar region (Croatia) revealed the presence of two mtDNA haplotypes, differing at two nucleotide positions (Table 3). The Balkan brown bear population is large and stable enough to harbour consistent levels of genetic variability, and analysing more samples will, it is predicted, reveal the existence of more mtDNA haplotypes. A study of mtDNA restriction fragment length polymorphism of North American brown bear (grizzly and Kodiak) mtDNA revealed the existence of five haplotypes, randomly distributed in the sampled area (Cronin et al., 1991).

The Alpine brown bear population shares its mtDNA with Croatian bears. The Alpine population (Province of Trento) has probably been isolated from the eastern main bear population for about a century (Castelli, 1935). The long-lasting process of eradication of local Alpine populations (Couturier, 1954) has apparently resulted in the progressive elimination of all but one of the existing mtDNA haplotypes.

If stochastic extinction of maternal lineages could be the cause of mtDNA monomorphism in the surviving western European bear populations, nonstochastic factors, in contrast, are required to explain the observed phylogeographic relationships among populations. The phylogenetic trees we have obtained are concordant with the data presented by Taberlet \& Bouvet (1994) in showing nonrandom relationships among the

Table 5 Pairwise differences among $D$-loop haplotypes (Table 3 )

\begin{tabular}{|c|c|c|c|c|c|c|c|c|c|c|c|c|c|}
\hline & \multicolumn{13}{|c|}{ Haplotypes } \\
\hline & 1 & 2 & 3 & 4 & 5 & 6 & 7 & 8 & 9 & 10 & 11 & 12 & 13 \\
\hline 1 & - & 1 & 3 & 8 & 9 & 3 & 10 & 4 & 8 & 8 & 6 & 7 & 9 \\
\hline 2 & 1.6 & - & 2 & 7 & 8 & 2 & 9 & 3 & 9 & 7 & 7 & 8 & 8 \\
\hline 3 & 4.8 & 3.2 & - & 10 & 10 & 4 & 11 & 5 & 9 & 7 & 9 & 10 & 10 \\
\hline 4 & 12.7 & 11.1 & 14.3 & - & 1 & 9 & 2 & 6 & 10 & 8 & 8 & 7 & 13 \\
\hline 5 & 14.3 & 12.7 & 15.9 & 1.6 & - & 10 & 1 & 7 & 11 & 9 & 9 & 8 & 14 \\
\hline 6 & 4.8 & 3.2 & 6.3 & 14.3 & 15.9 & - & 11 & 5 & 9 & 9 & 9 & 10 & 8 \\
\hline 7 & 15.9 & 14.3 & 17.5 & 3.2 & 1.6 & 17.5 & - & 8 & 10 & 8 & 8 & 7 & 15 \\
\hline 8 & 6.3 & 4.8 & 7.9 & 9.5 & 11.1 & 7.9 & 12.7 & - & 8 & 7 & 5 & 7 & 9 \\
\hline 9 & 12.7 & 14.3 & 14.3 & 15.9 & 17.5 & 14.3 & 15.9 & 12.7 & - & 4 & 4 & 5 & 13 \\
\hline 10 & 12.7 & 11.1 & 11.1 & 12.7 & 14.3 & 14.3 & 12.7 & 9.5 & 6.3 & - & 6 & 7 & 11 \\
\hline 11 & 9.5 & 11.1 & 14.3 & 12.7 & 14.3 & 14.3 & 12.7 & 9.5 & 6.3 & 9.5 & - & 3 & 11 \\
\hline 12 & 11.1 & 12.3 & 15.9 & 11.1 & 12.7 & 15.9 & 11.1 & 11.1 & 7.9 & 11.1 & 4.8 & - & 14 \\
\hline 13 & 14.3 & 12.7 & 15.9 & 20.6 & 22.2 & 12.7 & 23.8 & 14.3 & 20.6 & 17.5 & 12.5 & 22.2 & - \\
\hline
\end{tabular}

Upper (all transitions) and lower triangular matrices as in Table 4. 
different mtDNA haplotypes. European brown bear populations show a major genetic gap separating eastern populations (Romania, Russia, Lapland) from the Balkan and other western populations (Sweden, Italy, France, Spain). The average east-west $D$-loop sequence divergence is 7.5 per cent (Taberlet \& Bouvet, 1994). The western brown bear populations belong to three main maternal lineages: a northern lineage (Sweden); a south-eastern lineage (Croatia, Alps, Apennines); and a western lineage (Pyrenees and Cantabrian Mountains). The average $D$-loop sequence divergence among them is about 2.0 per cent. The correspondence between phylogenetic trees and the bears' geographical distribution suggests that the process of stochastic extinction of haplotypes within a population must have acted on pre-existing genetic divergence among populations. The causes of population divergence are not discernible now, although two processes could have produced the actual observed phylogeographic pattern: (i) isolation by distance, possibly enhanced by female phylopatry; and/or (ii) recolonization of suitable habitats after Pleistocene glaciations with populations originating from different refuges.
Fig. 2 UPGMA tree (obtained by the computer program MEGA (Kumar et al., 1993)) for the mtDNA $c y t-b$ sequences from Table 2. Numbers indicate the percentages of recurrence of the clusters after 1000 rounds of bootstrapping.
Fig. 3 UPGMA tree for the mtDNA $D$ loop sequences from Table 3. Numbers indicate the percentages of recurrence of the clusters after 1000 rounds of bootstrapping.
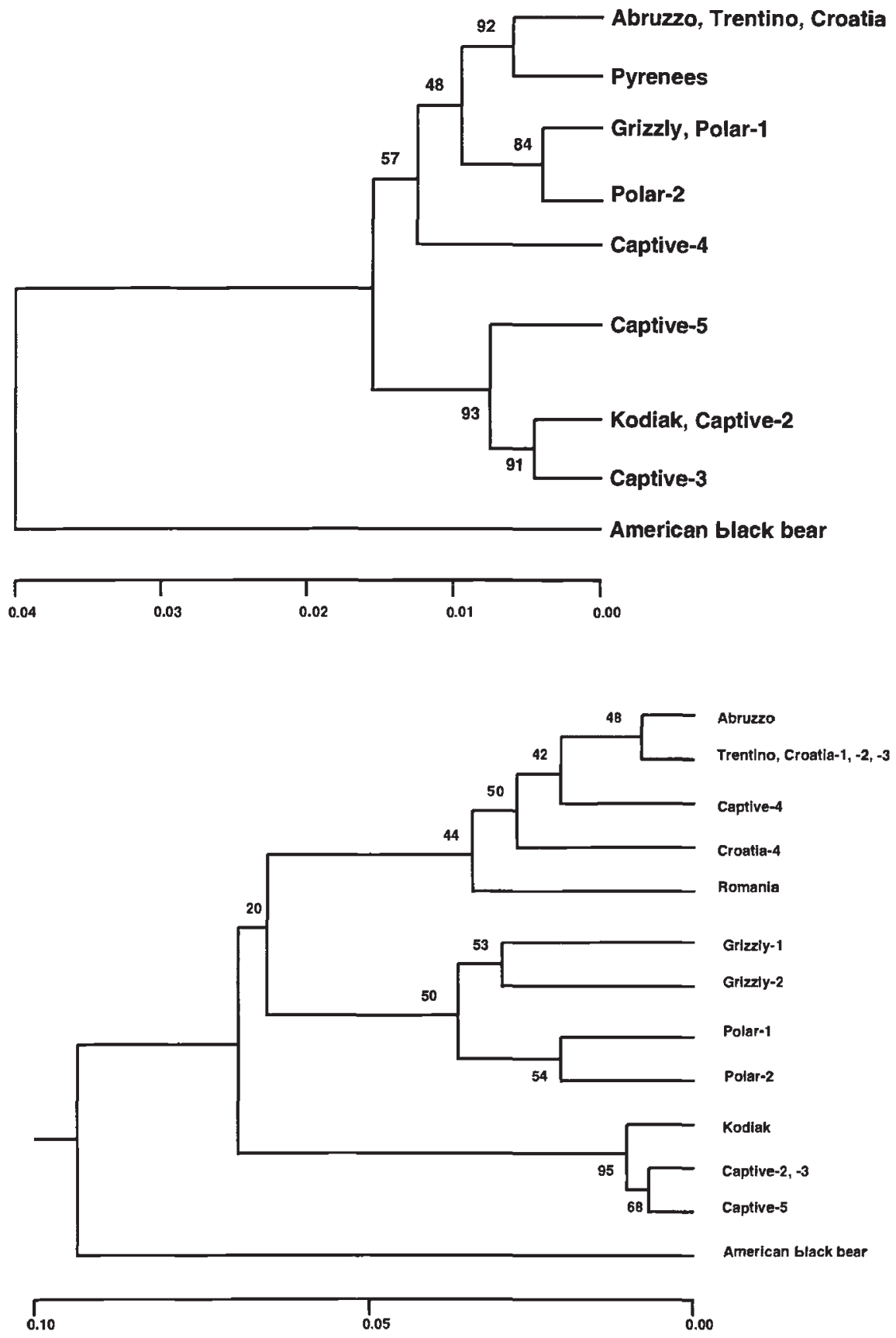


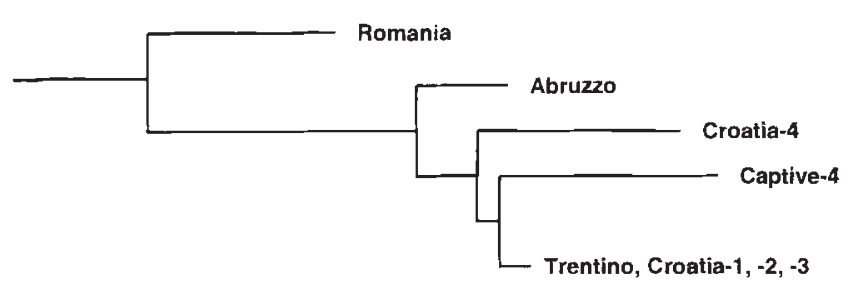

Fig. 4 Relationships within the western European brown bear mtDNA haplotypes obtained from the neighbour-joining procedure (Kumar et al., 1993), and mtDNA D-loop sequence divergence (Table 3 ).

Additional information on the evolutionary history of European brown bear populations will be gained when more samples are studied, and when nuclear hypervariable sequences (i.e. microsatellites) are analysed. Nevertheless, the available DNA sequence data allow inferences which are useful in the establishment of sound plans for the conservation of western European small bear populations. The effective population size $N_{\mathrm{e}}$ could be much smaller than $N_{\mathrm{o}}$ in brown bear (as well as in most vertebrate species). It is, therefore, possible that all the western European brown bear populations will not simply continue to lose genetic variability by random drift in future generations, but in addition could be prone to inbreeding depression (Lacy, 1992).

Furthermore, the described phylogeographic patterns allow the identification of major microevolutionary lineages among bear populations, and constitute the rationale for the choice of animals for restocking. The Cantabrian-Pyrenean bears constitute one phylogeographic complex of closely related populations. It comprises about 60-80 animals (Taberlet \& Bouvet, 1992) subdivided into four isolated populations. This complex could be managed as a single metapopulation with possible artificial migration and gene flow among subpopulations (Allendorf \& Servheen, 1986). The Apennine brown bears constitute a second phylogeographic unit, with unique mtDNA characters. It is probably a viable population, whose genetic integrity should be preserved. We suggest the enforcement of protection of the Apennine brown bears, avoiding restocking. The Alpine relict population is the remnant of a formerly continuous complex of populations ranging from the Alps to the Balkans. The Alpine-Croatian bears constitute a third phylogeographic unit, to which it may be possible to add populations belonging to other Balkanic regions (Slovenia, Bosnia Hercegovina) when available samples are analysed. Restocking the Alpine brown bears with animals from the Gorski Kotar (Croatia) population seems to be a genetically feasible choice, from the information so far available.
MtDNA sequencing allows the identification of the maternal lineages of bears of unknown origins, although the suitability of captive bears for restocking is questionable. Sequencing of PCR-amplified mtDNA has proved to be an efficient method of obtaining finegrained genetic data on brown bear populations. The possibility of amplifying DNA from hair roots or excrement collected in the field dramatically widens the range of application of molecular genetics to conservation biology.

\section{Acknowledgements}

We thank the Director of the Abruzzo National Park, who made possible the research project on Apennine brown bears, and F. Osti (Adamello-Brenta Provincial Park) for helping in sample collection. S. Kumar, K. Tamura and M. Nei kindly provided a copy of their computer program MEGA. J. Felsenstein provided PHYLIP.

\section{References}

ANDERSON, S., BANKIER, A. T., BARRELl, B. G., DeBRUIJN, M. H. L., COULSON, A. R., DROUIN, J., EPERON, I. C., NIERLICH, D. P., ROE, B. A., SANGER, F., SCHREIER, P. H., SMITH, A. J. H., STADEN, R. AND YOUNG, I. G. 1981. Sequence and organization of the human mitochondrial genome. Nature, 290, 457-465.

ALLENDORF, F. W. AND SERVHEEN, C. 1986. Genetics and conservation of grizzly bears. Trends Ecol. Evol., 1, 88-89.

AVISE, J. C. 1989. A role for molecular genetics in the recognition and conservation of endangered species. Trends Ecol. Evol, , 4, 279-281.

AVISE, J. C., ARNOLD, J., BALL, R. M., BERMINGHAM, E., LAMB, T., NEIGEL, J. E., REEB, C. A. AND SAUNDERS, N. C. 1987. Intraspecific phylogeography: the mitochondrial DNA bridge between population genetics and systematics. Annu. Rev. Ecol. Syst., 18, 489-522.

AVISE, J. C., NEIGEL, J. E. AND ARNOLD, J. 1984. Demographic influences on mitochondrial DNA lineage survivorship in animal populations. J. Mol. Evol, 20, 99-105.

BOSCAGLI, G. 1991. Metodo di valutazione dei popolamenti di orso col "field-tracking". Esperienze e problemi di applicazione in Italia. Atti II Sem. It. Censimenti Faun. Vertebr. Suppl. Ric. Biol, Selv., XVI, 545-547.

BosCAGLI, G. 1994. Brown bear and wolf in Italy. In: Schulte, R. (ed.) Proc. Int. Seminar on Threatened Big Mammals in Europe. Sunder, Hannover (in press.)

BROWN, W. M. 1985. The mitochondrial genome of animals. In: MacIntyre, R. (ed.) Molecular Evolutionary Genetics, pp. 95-130. Plenum Press, New York.

CAMARRA, J.-J. AND PARDE, J.-M. 1990. The brown bear in France - status and management in 1985. Aquilo Ser. Zool, 27, 93-96.

CASTELl, G. 1935. L'Orso Bruno nella Venezia Tridentina. Associazione Provinciale Cacciatori, Trento, Italy. 
Couturier, M. A. 1954. L'Ours Brun. Marcel Couturier, Grenoble, France.

CRONIN, M. A., AMSTRUP, S. C., GARNER, G. W. AND VYSE, E. R. 1991. Interspecific and intraspecific mitochondrial DNA variation in North American bears (Ursus). Can. J. Zool., 69, 2985-2992.

CURRY-LINDAHL, K. 1972. The brown bear (Ursus arctos) in Europe: decline, present distribution, biology and ecology. In: Herrero, S. (ed.) Bears - Their Biology and Management, New Series 23, pp. 74-80. IUCN Publications, Morges, Switzerland.

DEL CAMPO, J. C., MARQUiNEZ, J. L., NAVES, J. AND PALOMERO, G. 1990. The brown bear in the Cantabrian mountains. Aquilo Ser. Zool., 27, 97-101.

FEBBO, D. AND PELLEGRINI, M. 1990. The historical presence of the brown bear in the Apennines. Aquilo Ser. Zool., 27, 85-88.

FELSENSTEIN, J. 1989. PHYLIP 3.2 Manual. University of California Herbarium, Berkeley, CA.

HARRIS, R. B. AND ALLENDORF, F. W. 1989. Genetically effective population size of large mammals: an assessment of estimators. Conserv. Biol., 3, 181-191.

HILl1S, D. M., LARSON, A., DAVIS, S. K. AND ZIMMER, E. A. 1990. Nucleic acids III: Sequencing. In Hillis, D. M. and Moritz, C. (eds) Molecular Systematics, pp. 318-370. Sinauer Associates, Sunderland, MA.

HOSS, M., KOHN, M., PAABO, S., KNAUER, F. AND SCHROEDER, w. 1992. Excrement analysis by PCR. Nature, 319, 199.

HUBER, D. AND MORIC, s. 1989. Stete od mrkih medvjeda u Jugoslaviji. (Brown bear damage in Yugoslavia.) Proceedings of the third symposium "Savremeni pravci uzgoja divljaci". Savez veterinaria i veterinarskih tehnicara Jugoslavije, Beograd, 197-202. (In Croatian.)

KIMURA, M. 1980. A simple method for estimating evolutionary rates of base substitutions through comparative studies of nucleotide sequences. J. Mol. Evol., 16, 11-120.

KOCHER, T. D., THOMAS, W. K., MEYER, A., EDWARDS, S. V., PAABO, S., villablanCA, F. X. AND WILSON, A. C. 1989. Dynamics of mitochondrial DNA evolution in animals: amplification and sequencing with conserved primers. Proc. Natl. Acad. Sci. U.S.A., 86, 6196-6200.

KUMAR, S., TAMURA, K. AND NEI, M. 1993. MEGA. Molecular Evolutionary Genetic Analysis, Version 2.0. Institute of
Molecular Evolutionary Genetics, The Pennsylvania State University.

LACY, R. C. 1992. The effects of inbreeding on isolated populations: are minimum viable population sizes predictable? In Fiedler, P. L. and Jain, S. K. (eds) Conservation Biology: The Theory and Practice of Nature Conservation, Preservation and Management, pp. 277-296. Chapman and Hall, New York.

LANDE, R. 1988. Genetics and demography in biological conservation. Science, 241, 1455-1460.

MERTZANIS, G. 1990. The brown bear in Greece. Aquilo Ser. Zool., 27, 67-70.

OSTI, F. 1990. The brown bear in Trentino, Italy. Aquilo Ser. Zool., 27, 89-91.

SAIKI, R. K., GELFAND, D. H., STOFFEL, S., SCHARF, S. J., HIGUCHI, R., HORN, G. T., MULLIS, K. B. AND ERLICH, H. K. 1988. Primerdirected enzymatic amplification of DNA with a thermostable DNA polymerase. Science, 239, 487-491.

SER VHEEN, C. 1990. The status and conservation of the bears of the world. Int. Conf. Bear Research and Management, Monograph series no. 2, p. 32.

SHIELDS, G. F. AND KOCHER, T. D. 1991. Phylogenetic relationships of North American ursids based on analysis of mitochondrial DNA. Evolution, 45, 218-221.

SORENSEN, O. J. 1990. The brown bear in Europe in the mid 1980s. Aquilo Ser. Zool., 27, 3-16.

TABERLET, P. AND BOUVET, J. 1992. Génétique de l'ours brun des Pyrénées (Ursus arctos): premieres résultats. C. R. Acad. Sci. Paris, 314 (III), 15-21.

TABERLET, P. AND BOUVET, J. 1994. Mitochondrial DNA polymorphism, phylogeography, and conservation genetics of the brown bear Ursos arctos in Europe. Proc. R. Soc. B, 255, 195-200.

WALSh, P. S., METZGER, D. A. AND HIGUCHI, R. 1991. Chelex-100 as a medium for simple extraction of DNA for PCRbased typing from forensic material. BioTechniques, 10, 506-513.

WILSON, A. C., CANN, R. L., CARR, S. M., GEORGE, M., GYLLENSTEN, U. B., HELM-BYCHOWSK1, K. M., HIGUCHI, R. G., PALUMBI, S. R., PRAGER, E. M., SAGE, R. D. AND STONEKING, M. 1985. Mitochondrial DNA and two perspectives on evolutionary genetics. Biol. J. Linn. Soc., 26, 375-400.

WRIGHT, s. 1931. Evolution in Mendelian populations. Genetics, 16, 167-176. 